\title{
Application of a Noncarboxylated Dye Compound in a Dye-Sensitized Solar Cell Containing a Cyclodextrin Layer
}

\author{
Tatsuya Takeshita, Takao Umeda, Noriaki Oonishi, and Michihiro Hara \\ Department of Environmental and Food Sciences, Fukui University of Technology, 3-6-1 Gakuen, Fukui 910-8505, Japan \\ Correspondence should be addressed to Michihiro Hara; hara@fukui-ut.ac.jp
}

Received 16 April 2015; Accepted 28 May 2015

Academic Editor: Xudong Zhao

Copyright ( 2015 Tatsuya Takeshita et al. This is an open access article distributed under the Creative Commons Attribution License, which permits unrestricted use, distribution, and reproduction in any medium, provided the original work is properly cited.

We report the fabrication and characterization of a dye-sensitized solar cell containing a carboxymethyl- $\beta$-cyclodextrin sodium salt $\left(\mathrm{CM}-\beta\right.$-CD) layer and a noncarboxylated dye compound (tris $\left(2,2^{\prime}\right.$-bipyridyl)ruthenium(II)dichloride hexahydrate (Ru-dye)). The values of the incident photon-to-current conversion efficiency (IPCE) of the Ru-dye/CM- $\beta$-CD-containing device measured under 450 and $490 \mathrm{~nm}$ light irradiation were, respectively, 2.35\% and 3.33\%. The IPCE was due to the absorption of Ru-dye in ethanol solution. In contrast, the IPCE of the device that was prepared without the CM- $\beta$-CD layer measured under $450 \mathrm{~nm}$ irradiation was approximately three times smaller. Accordingly, the current findings demonstrate the application of a noncarboxylated dye compound in DSSCs incorporating a CM- $\beta-\mathrm{CD}$ layer.

\section{Introduction}

Dye-sensitized solar cells (DSSCs) have attracted much attention owing to their colorful appearance, low manufacturing cost, and application as a clean energy conversion device. Recently, various types of highly efficient DSSCs, such as organic thin film devices, flexible, and perovskite-based devices, have been produced at low cost [1-9]. The photoelectric conversion mechanism of DSSCs involves the following processes: (1) injection of electrons by the photoexcited chemically adsorbed dye molecule into the titanium oxide $\left(\mathrm{TiO}_{2}\right)$ layer and (2) reduction of the oxidized dye by a redox couple $\left(\mathrm{I} / \mathrm{I}_{3}{ }^{-}\right)$present in the electrolyte. The maximum conversion efficiency of DSSCs reported to date is $\sim 10 \%$ [10]; however, the conversion efficiency values remain to date significantly lower than the expected theoretical values [11] for inorganic solar cells. To address this issue, various parameters of the DSSC have been examined such as the photoanode, the counter electrode, and the optical properties of the dye and the electrolyte [12-19]. To improve cell performance, studies on the inclusion of a cyclodextrin- (CD) based layer in the photoanode of DSSCs, though rare, have been reported, as exemplified. The inclusion of complexes of $\beta$-cyclodextrin and 4-methyl-1-cyclohexane carboxylic acid has been reported to inhibit electron recombination of the injected electrons and redox couples near the surface of the bare $\mathrm{TiO}_{2}$ particles (employed as part of the photoanode) [20]. Additionally, the inclusion of [2] rotaxane formed by $\beta$-cyclodextrin and terpyridyl ruthenium complex achieved a cell conversion efficiency of $0.523 \%$ [21]. In contrast, the introduction of a dye molecule into DSSCs containing a CD layer via the inclusion effect of $\mathrm{CD}$ and the resulting cell performance have not been reported.

Presently, it is known that specific substituents, that is, carboxyl groups, are necessary for the chemical adsorption of the dye onto semiconductor $\mathrm{TiO}_{2}$. However, such a requirement limits the choice of the dye compound for application in DSSCs that could potentially limit progress in the performance of DSSCs. It is known that CD molecules have cavities of which the sizes are dependent on the number of glucose units ( $\alpha$-CD: 6 units; $\beta$-CD: 7 units; $\gamma$-CD: 8 units). The cavities can include various types of organic compounds by hydrophobic interaction in aqueous media. Thus, the incorporation of a CD layer in the device for the inclusion of dye molecules, not requiring specific (carboxylate) adsorptive groups, is expected to broaden the selection of dye 

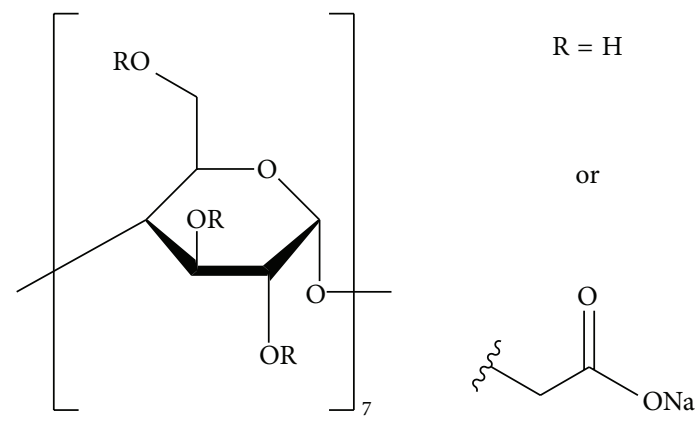

FIGURE 1: Molecular structure of carboxymethyl- $\beta$-cyclodextrin sodium salt $(\mathrm{CM}-\beta-\mathrm{CD})$.

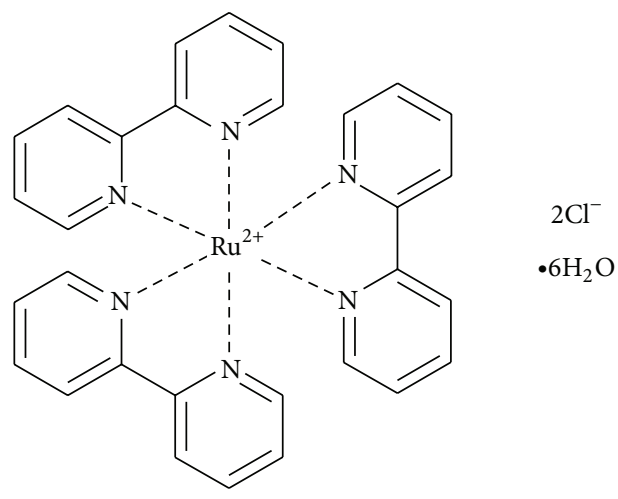

Figure 2: Molecular structure of tris(2,2' -bipyridyl)ruthenium(II) dichloride hexahydrate (Ru-dye).

molecules for application in DSSCs. Thus, offering a new strategy for the development of DSSCs with improved performance. Herein, we examined the fabrication and characterization of DSSCs featuring a CD (carboxymethyl- $\beta$ cyclodextrin sodium salt (CM- $\beta$-CD; Figure 1)) layer and the application of a noncarboxylated dye compound (tris- $\left(2,2^{\prime}\right.$ bipyridyl)ruthenium(II)dichloride hexahydrate (Ru-dye; Figure 2)) in DSSCs.

\section{Experimental}

2.1. Materials. The $\mathrm{TiO}_{2}$ paste was prepared by mixing $\mathrm{TiO}_{2}$ particles $(6.0 \mathrm{~g}$, Nippon Aerosil, Tokyo, Japan), polyethylene glycol ( $0.3 \mathrm{~g}$, Nacalai Tesque), acetylacetonate $(0.15 \mathrm{~mL}$, WAKO), and Triton X-100 (0.3 mL, Nacalai Tesque). Rudye was purchased from Tokyo Kasei (Japan). The electrolyte solution was purchased from Solaronix. CM- $\beta-C D$ was purchased from Sigma-Aldrich (Japan). The fluorinedoped tin oxide- (FTO-) coated glass with a sheet resistance of $9.3 \Omega / \mathrm{cm}^{2}$ was purchased from Asahi Glass Co., Ltd. Titanium tetrachloride $\left(\mathrm{TiCl}_{4}\right)$, benzene (spectrophotometric grade), and ethanol (spectrophotometric grade) were purchased from WAKO. All materials were used as received.

2.2. Device Fabrication. FTO-coated glass substrates were cleaned by successive washing in acetone (Nacalai Tesque,
Kyoto, Japan), assisted with sonication and acetone vapor. Then, the FTO-coated glass substrates were irradiated with ultraviolet light (Senjyu UV lamp VX-200HK002) for $20 \mathrm{~min}$. The $\mathrm{TiO}_{2}$ paste was transferred to a bottle, and churning was performed for 10 min using a churning deaerator (THINKY, AR-100). Then, the $\mathrm{TiO}_{2}$ paste was applied onto the FTOcoated glass substrates by a squeegee method and sintered for $1 \mathrm{~h} \mathrm{at} 500^{\circ} \mathrm{C}$. The temperature was set to rise from room temperature to $500^{\circ} \mathrm{C}$ for $20 \mathrm{~min}$. The FTO-coated glass substrates were then immersed in $0.1 \mathrm{M} \mathrm{TiCl}_{4}$ aqueous solution for $18 \mathrm{~h}$. After immersion, the substrates were dried with warm air, and sintered at $500^{\circ} \mathrm{C}$ for $1 \mathrm{~h}$. Two devices were fabricated in the absence and presence of a CM- $\beta$ $\mathrm{CD}$ layer (referred to as Ru-dye-containing and Ru-dye/CM$\beta$-CD-containing devices, resp.). Adsorption of CM- $\beta$-CD onto the $\mathrm{TiO}_{2}$-based DSSCs was performed by immersing the device in $2.9 \times 10^{-2} \mathrm{~g} / \mathrm{mL} \mathrm{CM}-\beta-\mathrm{CD}$ aqueous solution for $24 \mathrm{~h}$. Following immersion, the device was immersed in $3.0 \times 10^{-2} \mathrm{M}$ ethanol solution for $24 \mathrm{~h}$. Any residual dye solution was rinsed off with benzene. The counter electrode was fabricated by Pt sputtering the FTO-coated glass in $\mathrm{Ar}$ atmosphere.

2.3. Measurements. The current $(I)$-voltage $(V)$ profiles of the devices under light irradiation (light source comprised $500 \mathrm{~W}$ Xe lamp, USHIO UXL-500SX, and MT10-T monochromator; Bunkoukeiki Co., Ltd.) were recorded on an Advantest R6243 power source meter. A condenser lens was also used. The light intensity was measured using a power meter (Broadband Power/Energy Meter, 13PEM 001, Melles Griot). For the $I-V$ and light intensity measurements, an aperture mask of $0.28 \mathrm{~cm}^{2}$ was set on the device and power meter. The $I-V$ measurements were performed on an open cell. The short-circuit current density $\left(I_{\mathrm{sc}}\right)$, open-circuit voltage $\left(V_{\mathrm{oc}}\right)$, fill factor $(\mathrm{FF})$, and incident photon-to-current conversion efficiency (IPCE) were evaluated from the $I-V$ profiles. The absorption and fluorescence spectra of Ru-dye in ethanol solution, and the Ru-dye-containing and $\mathrm{Ru}$-dye/CM- $\beta$-CDcontaining devices were recorded on a spectrophotometer (Hitachi, U-3310) and a fluorescence spectrophotometer (PerkinElmer, LS55), respectively.

\section{Results and Discussion}

3.1. Steady-State Absorption and Fluorescence Spectra. Figure 3 shows the steady-state absorption spectrum (black line) of Ru-dye in ethanol solution. A maximum absorption peak was observed at $\sim 450 \mathrm{~nm}$ in the visible light region. A maximum fluorescence peak (red line) was observed at $\sim 606 \mathrm{~nm}$ using a $450-\mathrm{nm}$ light irradiation. The color (yellow) of the solution was consistent with a solution molar concentration in the order of $10^{-5} \mathrm{M}$.

3.2. Structure of the Ru-Dye/CM- $\beta$-CD Complex. The most stable minimum-energy structure obtained from the inclusion of Ru-dye into CM- $\beta$-CD, as calculated by MM2, is shown in Figure 4. The length and width of Ru-dye along the long and short axes were, respectively, $11.7 \AA$ and $9.6 \AA$. 


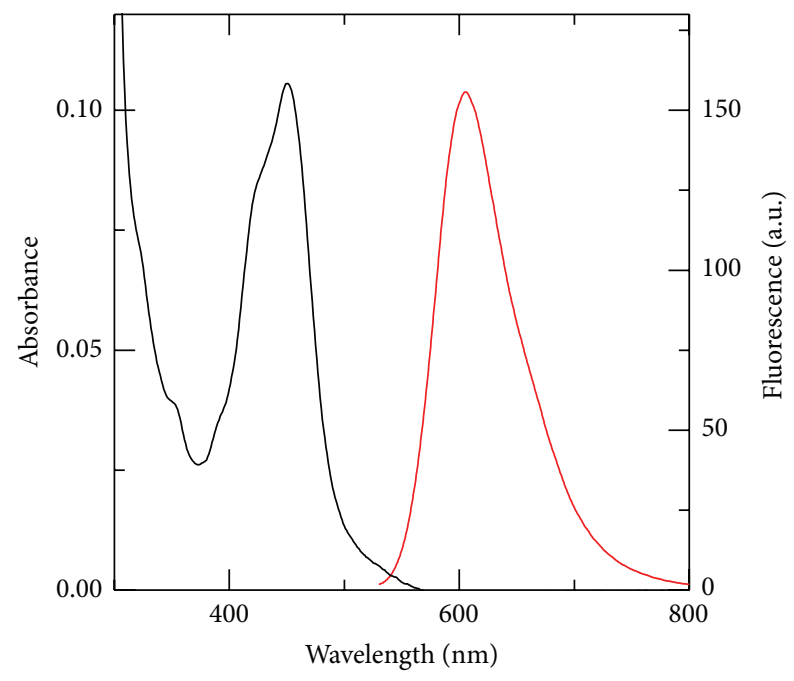

Figure 3: Absorption (black) and fluorescence (red) spectra of Rudye $\left(1.1 \times 10^{-5} \mathrm{M}\right)$ in ethanol.

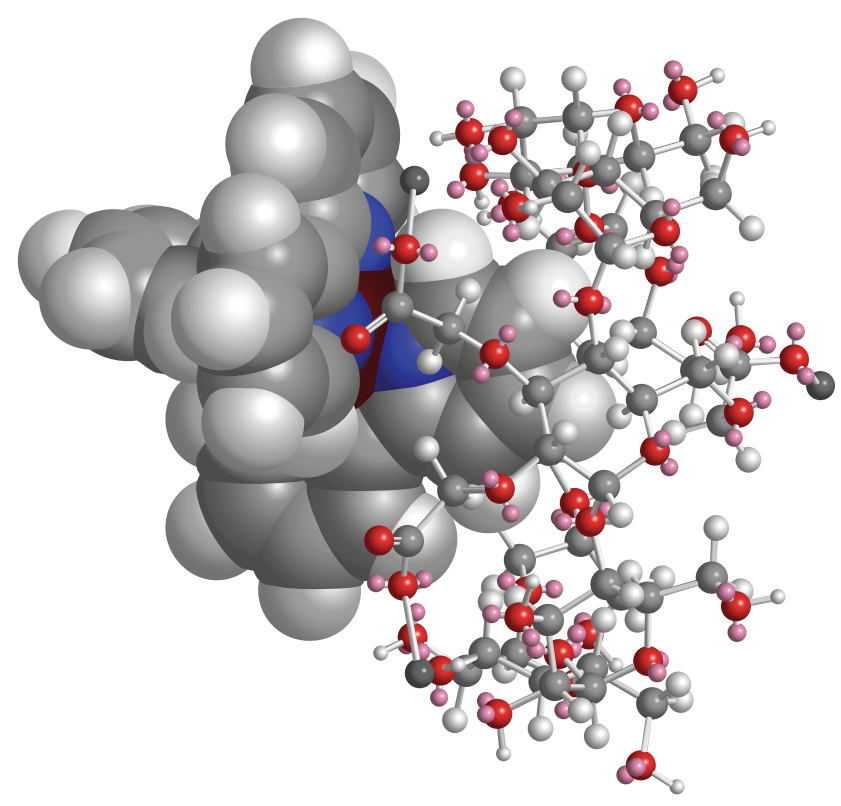

FIgURE 4: Minimum energy structure of the Ru-dye/CM- $\beta$-CD complex as calculated by MM2. The Ru-dye/CM- $\beta$-CD complex was modeled and subjected to geometry optimization to the most energetically stable structure using CS Chem3D.

The calculations indicated that only one of the pyridine rings of Ru-dye was incorporated into CM- $\beta$-CD while the two bipyridine units of Ru-dye protruded into the solution.

The photoelectrode surface of the device changed from white to yellow following immersion in the Ru-dye solution. The color of the photoelectrode surface was consistent with the color of Ru-dye in ethanol $\left(1.1 \times 10^{-5} \mathrm{M}\right)$. The adsorption of $\mathrm{Ru}$-dye onto the $\mathrm{TiO}_{2}$ surface is expected to occur via

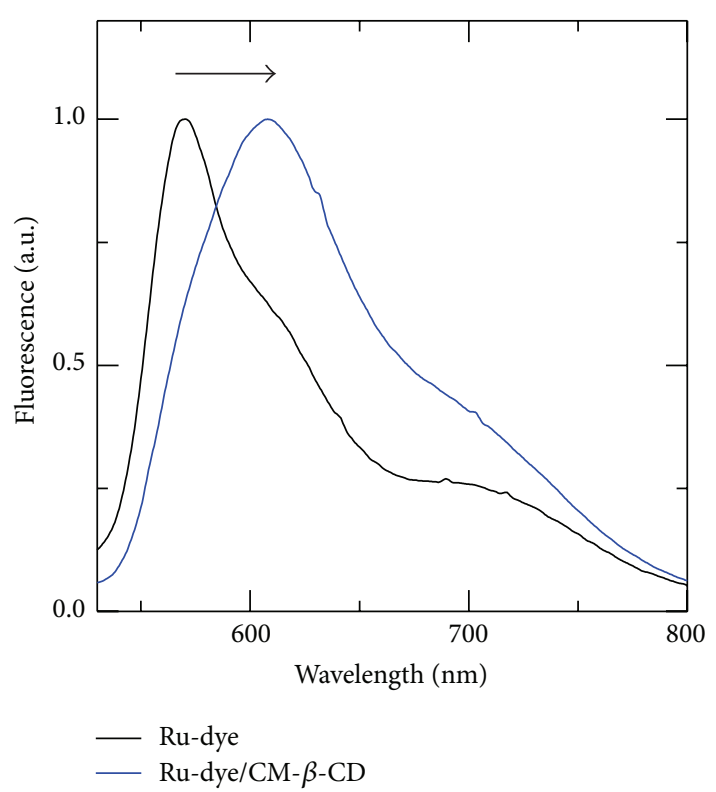

FIgURE 5: Fluorescence spectra of the Ru-dye-containing and $\mathrm{Ru}-$ dye/CM- $\beta$-CD-containing devices following excitation with $450 \mathrm{~nm}$ light irradiation.

chemical bonds between $\mathrm{TiO}_{2}$ and hexahydrate $\mathrm{Ru}$-dye. The fluorescence maximum peaks of the Ru-dye-containing and $\mathrm{Ru}$-dye/CM- $\beta$-CD-containing devices were observed at 570 and $\sim 608 \mathrm{~nm}$, using $450 \mathrm{~nm}$ light irradiation, respectively (Figure 5). In addition to the shift in the fluorescence maximum peak, the Ru-dye/CM- $\beta$-CD-containing device featured a broader fluorescence spectrum. For the $\mathrm{Ru}-$ dye-noncontaining and Ru-dye/CM- $\beta$-CD-noncontaining, fluorescence characteristics pertaining to $\mathrm{TiO}_{2}$ were not observed using an excitation wavelength of $450 \mathrm{~nm}$. This result indicated that $\mathrm{Ru}$-dye was incorporated into the cavities of CM- $\beta$-CD. Therefore, the result suggested the occurrence of adsorption of the carboxylic acid sodium salt group of CM$\beta$-CD onto $\mathrm{TiO}_{2}$ and inclusion of $\mathrm{Ru}$-dye into the cavities of $\mathrm{CM}-\beta-\mathrm{CD}$ (in addition to the direct adsorption of $\mathrm{Ru}$-dye onto $\mathrm{TiO}_{2}$ ).

3.3. Photovoltaic Performance of the DSSCs. The $I-V$ characteristics of the Ru-dye-containing and Ru-dye/CM- $\beta$-CDcontaining devices were measured under $450 \mathrm{~nm}$ light irradiation (Figure 6). The irradiation wavelength was selected according to the absorption peak of Ru-dye in ethanol solution. As observed, the Ru-dye-containing and Ru-dye/CM$\beta$-CD-containing devices featured $I-V$ properties. Here, $I-V$ characteristics were not affected by temperature from 15 to $25^{\circ} \mathrm{C}$ (i.e., at room temperature).

In contrast, the $\mathrm{TiO}_{2}$ DSSC prepared in the absence of a dye sensitizing layer (i.e., Ru-dye or Ru-dye/CM- $\beta$-CD) did not display any $I-V$ characteristics under $450 \mathrm{~nm}$ light irradiation. This confirms the onset of photoabsorption of 


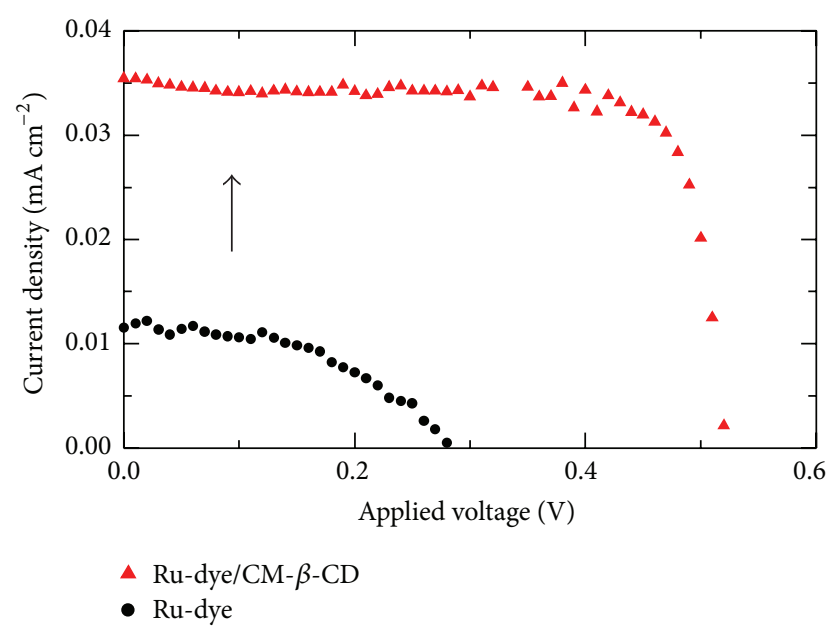

FIGURE 6: $I-V$ profiles of the Ru-dye-containing and Ru-dye/CM- $\beta$ $\mathrm{CD}$-containing devices measured under $450 \mathrm{~nm}$ light irradiation.

Ru-dye and Ru-dye/CM- $\beta$-CD for photoelectric conversion to occur (expressions (1) and (2)).

$$
\begin{array}{rl}
S_{0} & h \nu(\lambda=450 \mathrm{~nm}: 2.8 \mathrm{eV}) \longrightarrow S_{1}(2.2 \mathrm{eV}) \\
& \longrightarrow \text { photoelectric conversion }(\text { Ru-dye }) \\
S_{0}+h \nu(\lambda=450 \mathrm{~nm}: 2.8 \mathrm{eV}) \longrightarrow S_{1}(2.0 \mathrm{eV}) \\
\quad \longrightarrow \text { photoelectric conversion }(\mathrm{Ru}-\text { dye } / \mathrm{CM}-\beta-\mathrm{CD})
\end{array}
$$

The singlet excitation energy $\left(S_{1}\right)$ values of the $\mathrm{Ru}$ dye-containing and $\mathrm{Ru}$-dye/CM- $\beta$-CD-containing devices were calculated as 2.2 and $2.0 \mathrm{eV}$ from the respective fluorescence spectra. The $S_{1}$ values of the Ru-dye-containing and $\mathrm{Ru}$-dye/CM- $\beta$-CD-containing devices are smaller than the photon energy associated with $450 \mathrm{~nm}$ light irradiation (i.e., $2.8 \mathrm{eV}$ ), thereby implying the onset of photoelectric conversion (Figure 7).

The calculated IPCE values (under $450 \mathrm{~nm}$ light irradiation) of the Ru-dye-containing and $\mathrm{Ru}$-dye/CM- $\beta$ CD-containing devices were $0.77 \%$ and $2.35 \%$, respectively (Table 1). The higher IPCE of the Ru-dye/CM- $\beta$-CDcontaining device was attributed to the increase in the concentration of Ru-dye in the device as a result of the $\mathrm{CM}-\beta-\mathrm{CD}$ inclusion effect discussed earlier. Additionally, higher $V_{\mathrm{oc}}$ and FF values were observed for the Ru-dye/CM$\beta$-CD-containing device when compared with those of the Ru-dye-containing device. Improvements in the $V_{\text {oc }}$ and FF were attributed to the reduced electron recombination processes with $\mathrm{I}_{3}{ }^{-}$in the electrolyte and electrons of the bare surface of the $\mathrm{TiO}_{2}$ particles in the presence of the Ru-dye/CM- $\beta$-CD layer [20].

To confirm the photoabsorption of the Ru-dye/CM- $\beta$ $\mathrm{CD}$-containing device in the visible light region, the $I-V$ profiles of the device and associated IPCE values were calculated in the visible light region at intervals of $10 \mathrm{~nm}$. The $I-V$ profile of the device measured under $580 \mathrm{~nm}$ light irradiation is also included (Figure 8, black markers). Maximum IPCE of the $\mathrm{Ru}$-dye/CM- $\beta$-CD-containing device was obtained under
TABLE 1: Photovoltaic performance of devices prepared in the absence and presence of a CM- $\beta$-CD layer.

\begin{tabular}{lccccc}
\hline Device & $\begin{array}{c}\lambda \\
(\mathrm{nm})\end{array}$ & FF & $\begin{array}{c}V_{\text {oc }} \\
(\mathrm{V})\end{array}$ & $\begin{array}{c}I_{\mathrm{sc}} \\
\left(\mathrm{mA} / \mathrm{cm}^{2}\right)\end{array}$ & $\begin{array}{c}\text { IPCE } \\
(\%)\end{array}$ \\
\hline Ru-dye & 450 & 0.49 & 0.28 & 0.012 & 0.77 \\
Ru-dye/CM- $\beta$-CD & 450 & 0.78 & 0.52 & 0.035 & 2.35 \\
& 490 & 0.81 & 0.54 & 0.062 & 3.33 \\
\hline
\end{tabular}
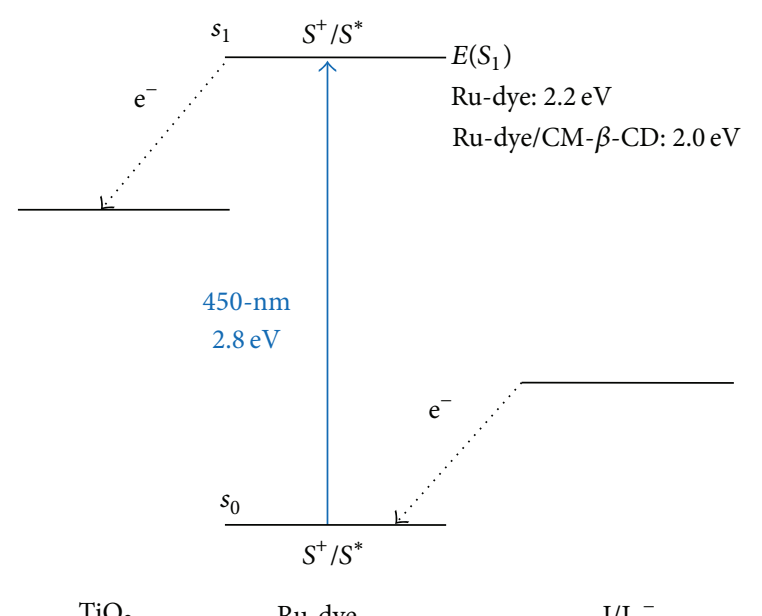

FIGURE 7: Energy diagrams of the Ru-dye-containing and $\mathrm{Ru}-$ dye/CM- $\beta$-CD-containing devices showing the ground and excited states of the devices.

$490 \mathrm{~nm}$ light irradiation (Figure 8, blue markers). The $I_{\mathrm{sc}}, V_{\mathrm{oc}}$, and $\mathrm{FF}$ values obtained under $490 \mathrm{~nm}$ light irradiation are also listed in Table 1 . The absorption spectrum of Ru-dye in ethanol and the IPCE spectrum of the Ru-dye/CM- $\beta$-CDcontaining device were compared (Figure 9). As observed, the IPCE plot of the Ru-dye/CM- $\beta$-CD-containing device and absorption spectrum of Ru-dye in ethanol were comparable, which indicates that photoconversion efficiency is due to the photoabsorption of Ru-dye. However, the maximum IPCE peak was shifted by $40 \mathrm{~nm}$ relative to the absorption peak of Ru-dye in ethanol. This result suggests that Ru-dye is stabilized by polarity of the ethanol solution. Therefore, $\mathrm{Ru}-$ dye/CM- $\beta-\mathrm{CD}$ was photoabsorbed and acted as a sensitizing dye (Scheme 1).

\section{Conclusion}

We demonstrated the fabrication and characterization of a noncarboxylated Ru-dye-based DSSC incorporating a CM$\beta$-CD layer. The formation of the Ru-dye/CM- $\beta$-CD inclusion complex was investigated by fluorescence spectroscopy. The fluorescence maximum peaks of the Ru-dye-containing and $\mathrm{Ru}$-dye/CM- $\beta$-CD-containing devices were observed at $\sim 570$ and $\sim 608 \mathrm{~nm}$ using an excitation wavelength of $450 \mathrm{~nm}$. The shift in the maximum fluorescence peak of the CM$\beta$-CD layer-containing device indicated that Ru-dye was incorporated into the CM- $\beta$-CD layer. The $I-V$ characteristics of the $\mathrm{Ru}$-dye/CM- $\beta$-CD-containing device measured under 


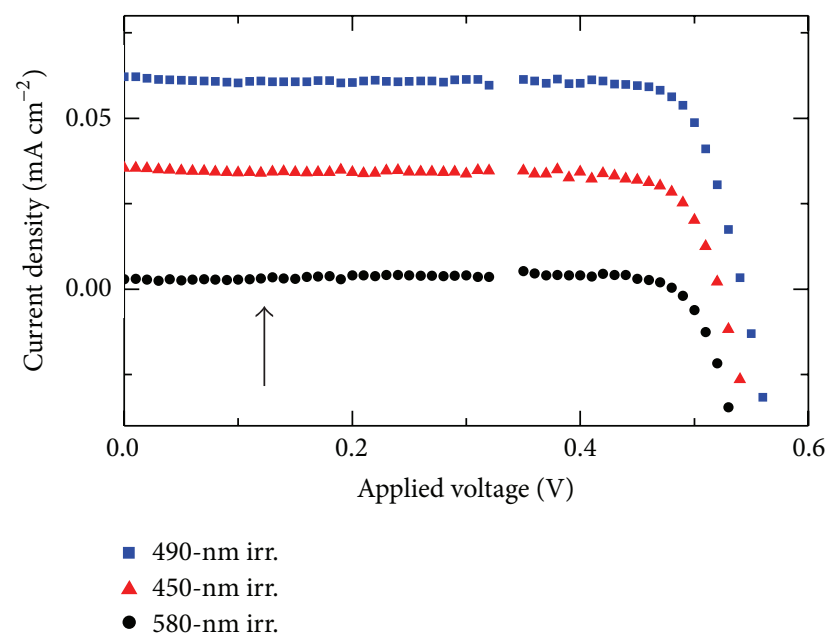

Figure 8: $I$ - $V$ profiles of the $\mathrm{Ru}$-dye/CM- $\beta$-CD-containing device measured under 580,490 , and $450 \mathrm{~nm}$ light irradiation.

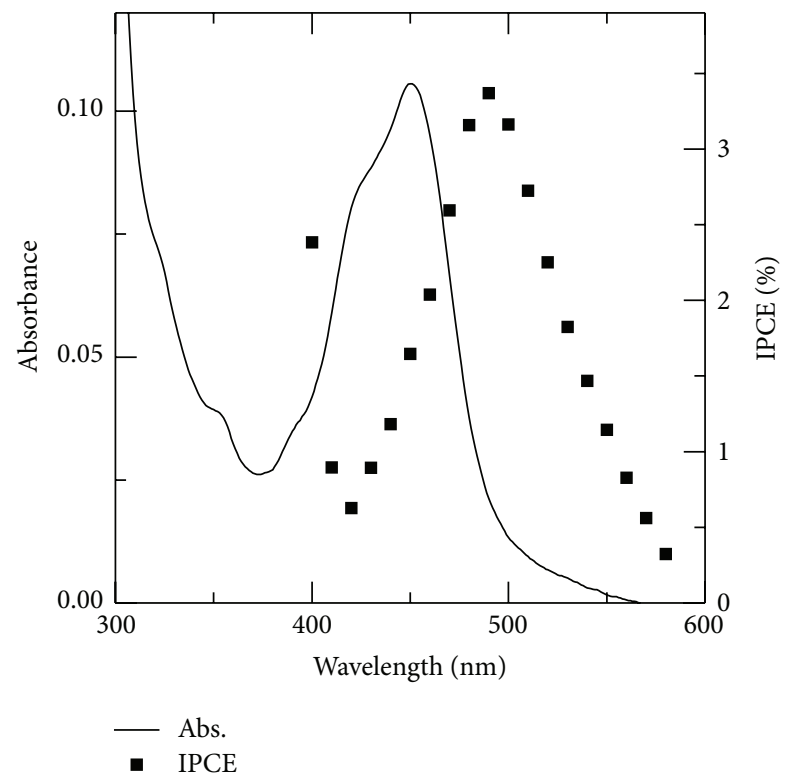

FIGURE 9: Plots of IPCE versus wavelength of Ru-dye/CM- $\beta$-CDcontaining device and absorption spectrum of Ru-dye $\left(1.1 \times 10^{-5} \mathrm{M}\right)$ in ethanol.

$450 \mathrm{~nm}$ light irradiation confirmed the photoabsorption of $\mathrm{Ru}-$ dye/CM- $\beta$-CD relative to the $I-V$ results of device fabricated in the absence of $\mathrm{Ru}$-dye $\left(\mathrm{TiO}_{2}\right.$ only), whereby photoabsorption was not observed. The IPCE was due to the absorption of Ru-dye. And the IPCE plot obtained at varying irradiation wavelengths nearly overlapped with the absorption spectrum of Ru-dye in ethanol measured at the same irradiation wavelengths. Additionally, the $\mathrm{Ru}-$ dye/CM- $\beta$-CD-based device featured improved photovoltaic performance.

In summary, the inclusion of the $\mathrm{CM}-\beta-\mathrm{CD}$ layer improved the photovoltaic performance of the cell containing a noncarboxylated dye compound. The findings present

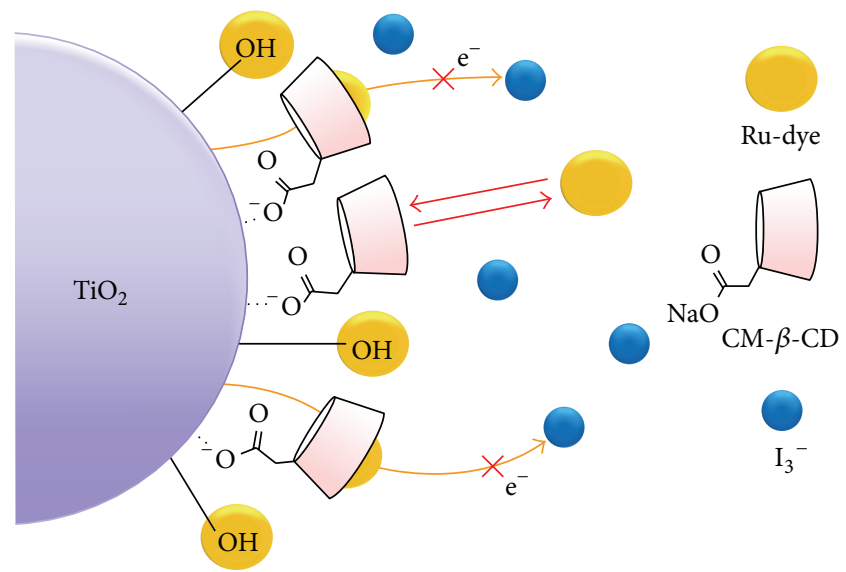

Scheme 1: Model of the adsorption of Ru-dye/CM- $\beta$-CD complex onto $\mathrm{TiO}_{2}$.

a gateway to future studies involving the optimization of devices incorporating a CM- $\beta$-CD layer and investigation of a wider selection of noncarboxylated compounds to achieve high photovoltaic efficiencies. Additionally, CM- $\beta$-CD-based DSSCs offer potential for IPCE control and enhancement of performance in the absence of external stimulus response molecules.

\section{Conflict of Interests}

The authors report that there is no conflict of interests.

\section{Acknowledgment}

This research was supported by the Ministry of Education, Culture, Sports, Science and Technology Program for the Strategic Research Foundation at Private Universities (20112016).

\section{References}

[1] M.-D. Zhang, H.-X. Xie, X.-H. Ju et al., "D-D- $\pi-A$ organic dyes containing $4,4^{\prime}$-di(2-thienyl)triphenylamine moiety for efficient dye-sensitized solar cells," Physical Chemistry Chemical Physics, vol. 15, no. 2, pp. 634-641, 2013.

[2] L. Kranz, C. Gretener, J. Perrenoud et al., "Doping of polycrystalline CdTe for high-efficiency solar cells on flexible metal foil," Nature Communications, vol. 4, article 2306, 2013.

[3] H.-M. Lee, S.-B. Kang, K.-B. Chung, and H.-K. Kim, “Transparent and flexible amorphous In-Si-O films for flexible organic solar cells," Applied Physics Letters, vol. 102, no. 2, Article ID 021914, 2013.

[4] G. J. Hedley, A. J. Ward, A. Alekseev et al., "Determining the optimum morphology in high-performance polymer-fullerene organic photovoltaic cells," Nature Communications, vol. 4, article 2867, 2013.

[5] J. Chang, Z. Ming Kam, Z. Lin, C. Zhu, J. Zhang, and J. Wu, " $\mathrm{TiO}_{x} / \mathrm{Al}$ bilayer as cathode buffer layer for inverted organic solar cell," Applied Physics Letters, vol. 103, no. 17, Article ID 173303, 2013. 
[6] J. Zhao, X. Yang, M. Cheng, S. Li, and L. Sun, "New organic dyes with a phenanthrenequinone derivative as the $\pi$-conjugated bridge for dye-sensitized solar cells," The Journal of Physical Chemistry C, vol. 117, no. 25, pp. 12936-12941, 2013.

[7] Q. Feng, X. Jia, G. Zhou, and Z.-S. Wang, "Embedding an electron donor or acceptor into naphtho[2,1-b:3,4-b'] dithiophene based organic sensitizers for dye-sensitized solar cells," Chemical Communications, vol. 49, no. 67, pp. 7445-7447, 2013.

[8] O. Malinkiewicz, A. Yella, Y. H. Lee et al., "Perovskite solar cells employing organic charge-transport layers," Nature Photonics, vol. 8, no. 2, pp. 128-132, 2014.

[9] D. Liu and T. L. Kelly, "Perovskite solar cells with a planar heterojunction structure prepared using room-temperature solution processing techniques," Nature Photonics, vol. 8, no. 2, pp. 133-138, 2014.

[10] B. O’Regan and M. Graetzel, "A low-cost, high-efficiency solar cell based on dye-sensitized colloidal $\mathrm{TiO}_{2}$ films," Nature, vol. 353, no. 6346, p. 737, 1991.

[11] Z. Yue, H. Shen, Y. Jiang et al., "Large-scale black multicrystalline silicon solar cell with conversion efficiency over 18 \%," Applied Physics A, vol. 116, no. 2, pp. 683-688, 2014.

[12] Y.-S. Chien, P.-Y. Yang, I.-C. Lee et al., "Enhanced efficiency of the dye-sensitized solar cells by excimer laser irradiated carbon nanotube network counter electrode," Applied Physics Letters, vol. 104, no. 5, Article ID 051114, 2014.

[13] S. G. Shin, K. H. Kim, C. W. Bark, and H. W. Choi, "Improving the performance of dye-sensitized solar cells by using the conversion luminescence of a phosphor," Journal of the Korean Physical Society, vol. 65, no. 10, pp. 1682-1686, 2014.

[14] S. G. Shin, C. W. Bark, and H. W. Choi, "The effect of phosphor$\mathrm{TiO}_{2}$ layer on the performance of dye-sensitized solar cells," Molecular Crystals and Liquid Crystals, vol. 600, no. 1, pp. 4755, 2014.

[15] S.-J. Kim, H.-S. Ko, G.-H. Jeong, K.-H. Park, J.-J. Yun, and E.M. Han, "Fabrication and characterization of reduced graphene oxide counter electrode for dye-sensitized solar cells," Molecular Crystals and Liquid Crystals, vol. 598, no. 1, pp. 1-5, 2014.

[16] D. Maheswari and P. Venkatachalam, "Enhanced efficiency and improved photocatalytic activity of $1: 1$ composite mixture of $\mathrm{TiO}_{2}$ nanoparticles and nanotubes in dye-sensitized solar cell," Bulletin of Materials Science, vol. 37, no. 6, pp. 1489-1496, 2014.

[17] M. Imperiyka, A. Ahmad, S. A. Hanifah, A. A. Umar, N. S. Mohamed, and M. Y. Rahman, "Photo-polymerization of methacrylate based polymer electrolyte for dye-sensitized solar cell," Journal of Polymer Engineering, vol. 34, no. 8, pp. 695-702, 2014.

[18] F. Gu, W. Huang, S. Wang, X. Cheng, Y. Hu, and P. S. Lee, "Open-circuit voltage improvement in tantalum-doped $\mathrm{TiO}_{2}$ nanocrystals ," Physical Chemistry Chemical Physics, vol. 16, no. 47, pp. 25679-25683, 2014.

[19] M. Z. Razali, H. Abdullah, S. Shaari, and M. R. Taha, "Preparation of photoelectrode $\mathrm{CNT} / \mathrm{TiO}_{2}$ doped $\mathrm{ZnO}$ nanocomposite by sol-gel method for dye-sensitized solar cell," Optoelectronics and Advanced Materials, Rapid Communications, vol. 8, no. 5-6, pp. 451-456, 2014.

[20] S. Park, H. Kim, S. Jang, and J. Won, "Effects of cyclodextrin complexes acting as barriers on $\mathrm{TiO}_{2}$ nanoparticles in DSSCs," Journal of Photochemistry and Photobiology A: Chemistry, vol. 283, pp. 17-21, 2014.

[21] Y. Ou, G. Chen, J. Yin, G.-A. Yu, and S. H. Liu, "Rotaxane based on terpyridyl bimetal ruthenium complexes and $\beta$-cyclodextrin as organic sensitizer for dye-sensitized solar cells," Journal of Coordination Chemistry, vol. 64, no. 17, pp. 3062-3067, 2011. 

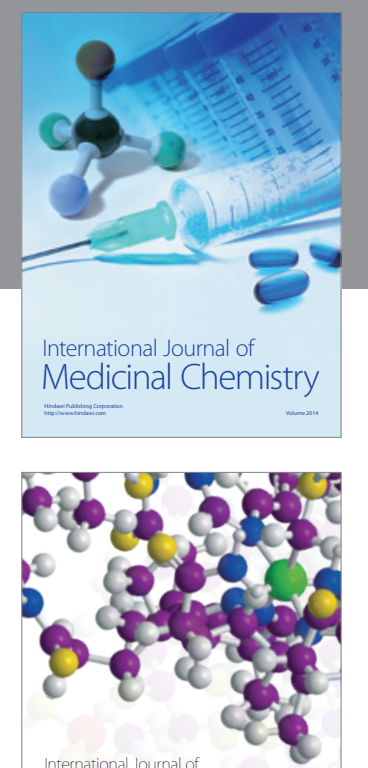

\section{Carbohydrate} Chemistry

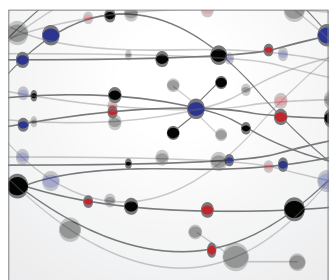

The Scientific World Journal
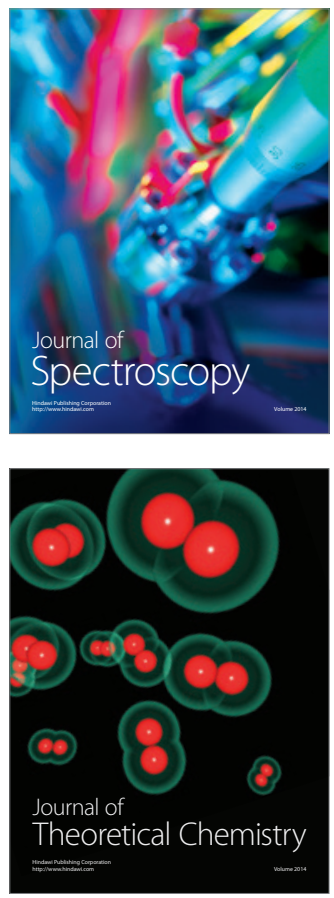
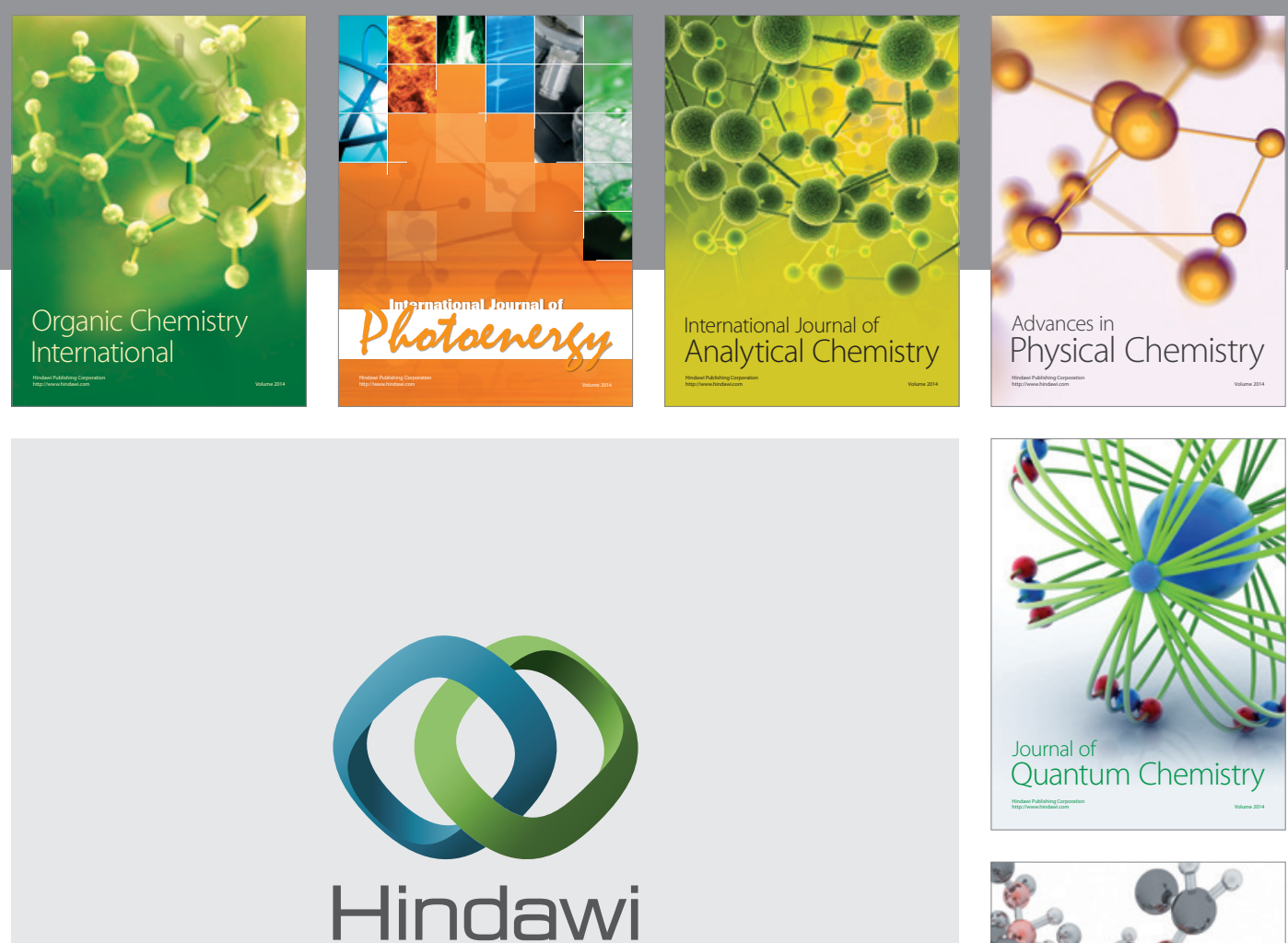

Submit your manuscripts at

http://www.hindawi.com

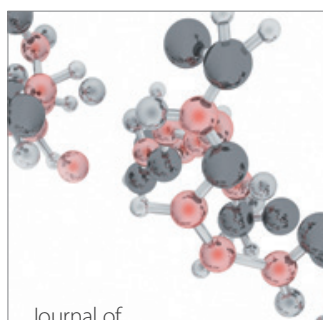

Analytical Methods

in Chemistry

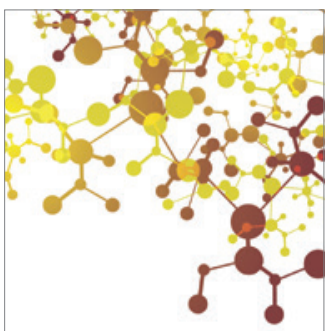

Journal of

Applied Chemistry

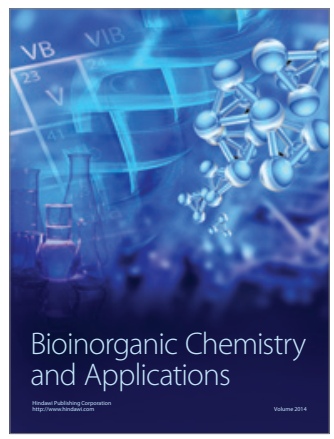

Inorganic Chemistry
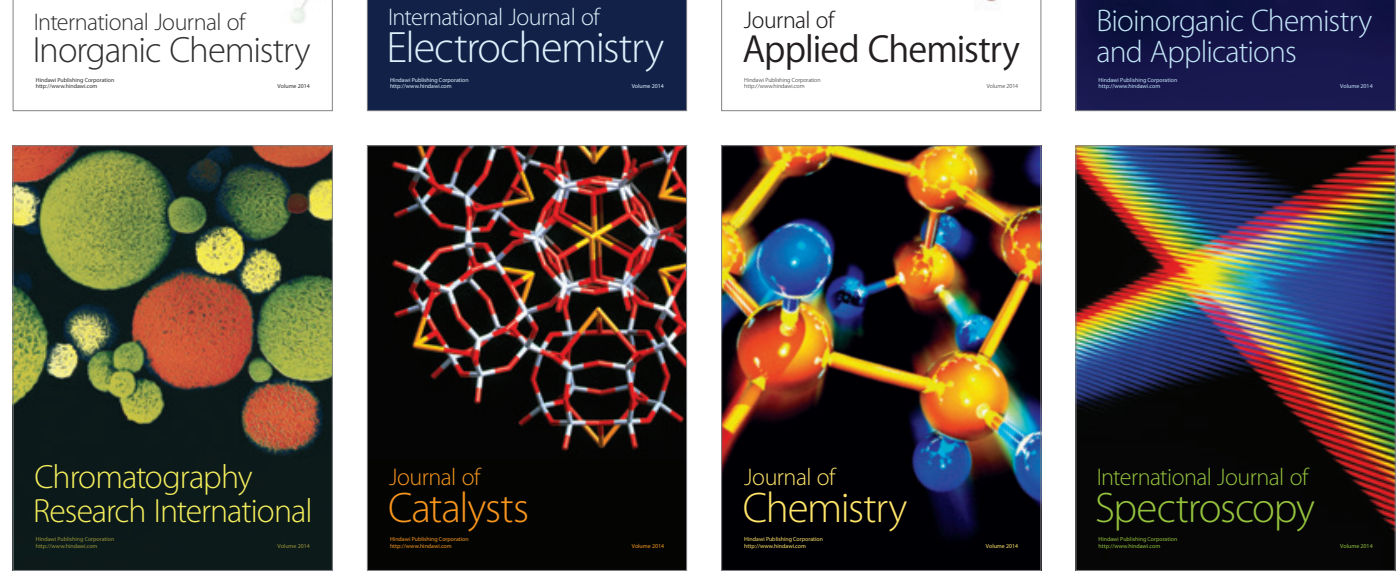